\title{
Analysis of Customization Strategy for E-Commerce Operation Based on Big Data
}

\author{
Su Chen \\ School of International Trade and Economics, Ningbo University of Finance and Economics, Ningbo 315175, China \\ Correspondence should be addressed to Su Chen; suchen@nbufe.edu.cn
}

Received 3 October 2020; Revised 20 October 2020; Accepted 5 February 2021; Published 26 February 2021

Academic Editor: Hongju Cheng

Copyright (c) 2021 Su Chen. This is an open access article distributed under the Creative Commons Attribution License, which permits unrestricted use, distribution, and reproduction in any medium, provided the original work is properly cited.

\begin{abstract}
In order to improve the efficiency of customization and reduce the cost of customization under Big data environment, this paper uses cost-sharing contract, pricing mechanism, Hotelling model, and game theory tools and research methods, for C2B Electronic Commerce (e-commerce) mode of Supply Chain Pricing Strategy for in-depth discussion. This paper first gives the architecture of the customization service system based on big data. The paper studies the game equilibrium of supply chain members under four scenarios: centralized decision-making, decentralized decision-making, C2B-dominated decision-making, and traditional enterprise-dominated decision-making in a supply chain composed of a supplier and C2B e-commerce enterprises with horizontal price competition, and examines the cross-price. Important parameters such as impact coefficient, impact coefficient of effort degree of personalized customization, and so on have an impact on variables such as effort degree of personalized customization, retail price, and profit of supply chain members of $\mathrm{C} 2 \mathrm{~B}$ e-commerce enterprises. Research shows that with the increase of cross-price impact coefficient, $\mathrm{C} 2 \mathrm{~B}$ e-commerce will enhance its personalized customization efforts in different situations in order to pursue higher profits.
\end{abstract}

\section{Introduction}

With the continuous development and popularization of Internet technology, e-commerce has begun to challenge the traditional business transaction model and become an important market force, affecting the development process of the world economy $[1,2]$. E-commerce is a new business model based on the Internet as a trading platform. Since its appearance in the 1990s, its development momentum has been very rapid. Under the circumstance of making full use of Internet resources, e-commerce has incomparable advantages over the traditional business model $[3,4]$. It can realize cross-regional and all-weather business, with a complete range of goods, easy retrieval, low cost, and can provide personalized services for consumers. All these are the unique features of electronic commerce born on the Internet [5].

C2B module customization: this $\mathrm{C} 2 \mathrm{~B}$ model is mainly to meet the personalized needs of specific groups formed a model, with a strong market target orientation; usually, the success rate of marketing will be relatively large [6]. Typically, such as Haier Home Appliances Customization Service,
Blue Orange Mobile Phone, etc. are trying this kind of service. Consumers choose and combine the performance of the components according to their own needs when placing an order, and then, the manufacturer produces according to the combination requirements in the order [7]. However, the $\mathrm{C} 2 \mathrm{~B}$ mode of this module combination requires higher production efficiency of the enterprise production line, and this so-called function combination cannot really integrate the opinions of consumers. Consumers' choice is just to arrange and combine the existing functions within the range given by the manufacturer [8]. Restrictions on objective conditions of the needs of consumers $[9,10]$. Mass customization refers to the new mode of production produced by enterprises in order to adapt to the new market environment. With the diversification and customization of products aggravating economic value and strategic advantages, the demand of consumer personalized customization needs to be urgently met [11]. The realization of mass customization is facilitated. Mass customization is an important way to enhance the competitiveness of enterprises, so more and more supply chain enterprises also realize the importance 
of pricing in the case of mass customization. Some researchers study the product pricing problem of mass customizer and distributor under the condition that product price and lead time affect demand and analyze the lead time strategy and optimal pricing strategy of supply chain enterprises under centralized decision, decentralized decision, and mass customizer-led decision. Based on this, a commission contract is proposed. It can effectively coordinate the lead time and pricing problem of mass customization supply chain. Literature investigates the product pricing problem under mass customization and analyzes the time problem of price change from the perspective of internal operation decision-making in order to achieve the goal of maximizing profit [12]. Under the condition of certain mass customization capability, how to analyze the individual demand of consumers and determine the degree of customization effort of products are discussed. E-commerce refers to the use of any information and communication technology for any form of business or management operations or information exchange. The relationship between enterprise income and customer satisfaction and customization degree is discussed. The model and algorithm of optimizing output are established, and the optimum degree of customization is determined to maximize profits [13].

In order to improve the efficiency of customization and reduce the cost of customization under Big data environment, this paper uses cost-sharing contract, pricing mechanism, Hotelling model, and game theory tools and research methods, for C2B Electronic Commerce (e-commerce) mode of Supply Chain Pricing Strategy for in-depth discussion. This paper first gives the architecture of the customization service system based on big data. The paper studies the game equilibrium of supply chain members under four scenarios: centralized decision-making, decentralized decision-making, C2B-dominated decision-making, and traditional enterprise-dominated decision-making in a supply chain composed of a supplier and $\mathrm{C} 2 \mathrm{~B}$ e-commerce enterprises with horizontal price competition, and examines the cross-price. Important parameters such as impact coefficient, impact coefficient of effort degree of personalized customization, and so on have an impact on variables such as effort degree of personalized customization, retail price, and profit of supply chain members of $\mathrm{C} 2 \mathrm{~B}$ e-commerce enterprises. Research shows that with the increase of cross-price impact coefficient, C2B e-commerce will enhance its personalized customization efforts in different situations in order to pursue higher profits [14].

\section{Electronic Commerce's Customization System Based on Network Big Data}

2.1. The Big Data Platform for Electronic Commerce. The implementation of $\mathrm{C} 2 \mathrm{~B}$ customization mode requires the active participation of consumers, but the participation of consumers requires enterprises to spend more energy to achieve, which will inevitably cause a burden on the cost of enterprises. However, under the influence of the big data era, we can make full use of the collected large data to realize the "big data customization" C2B mode [15]. This mode is actually based on the full analysis of the collected massive data, mining valuable information for enterprises, usually consumers' consumption habits. Methods and characteristics, and then the integration of various social resources based on large data extracted from useful information for product production. The intelligent tourism system architecture based on big data technology is shown in Figure 1.

The data that can be used in the personalization of e-commerce are mainly click traffic data of website and mobile device data. In our daily life, we can also integrate the personal data of e-commerce users through some records with the characteristics of identifying users to form a complete set of personalized e-commerce recommendation data. For effective marketing and promotion, every click and its time on the Internet are recorded, and with this data, service providers can carefully analyze user access patterns to provide more targeted services. User personalized behaviour data mainly include social network, logged-in sites, page stay and news, search keywords, mobile phone click applications, and LBS-based user behaviour data.

E-commerce data is becoming more and more huge, traditional databases will have query bottlenecks, whether in storage or inquiry, there are performance bottlenecks, user applications and analysis results show a trend of integration, real-time and response time requirements are getting higher and higher, the model used is becoming more and more complex, and the amount of calculation increases exponentially, traditional skills. Unable to deal with large data: mobile customer data volume to TB level; Oracle database SQL statements can get results, but hope to further improve efficiency.

According to the existing personalized recommendation structure, the improved E-commerce can be divided into four modules: data integration, data preprocessing, model algorithm, and online recommendation of products. Starting from the data integration, the user's personal information is collected from all aspects, and the user's personalized data is fully grasped from the data source. Then, the formatted data are stored in the database through data preprocessing, and the effective analysis data are extracted by e-commerce. Using e-commerce personalized recommendation technology, by matching the existing recommendation patterns, a certain rule is stored in the database. When the user browses the relevant information in the e-commerce website, the recommendation information is returned to the client through the current session to complete an effective e-commerce personalized recommendation activity.

2.2. CBR Architecture of Customization Service in Electronic Commence. CBR architecture of customization service in electronic commerce is shown in Figure 2.

The theory of customization service is to adjust the information organization mode to provide the best service according to the specific consumption mode of each user. But the convergence of the crowd consumption shows that it is feasible to divide the consumption behaviour mode according to the user group. For large-scale e-commerce service providers, it does not reduce the quality of customized service. On the premise of quantity, this partition can greatly reduce information load. CBR is precisely an idea to solve new problems 


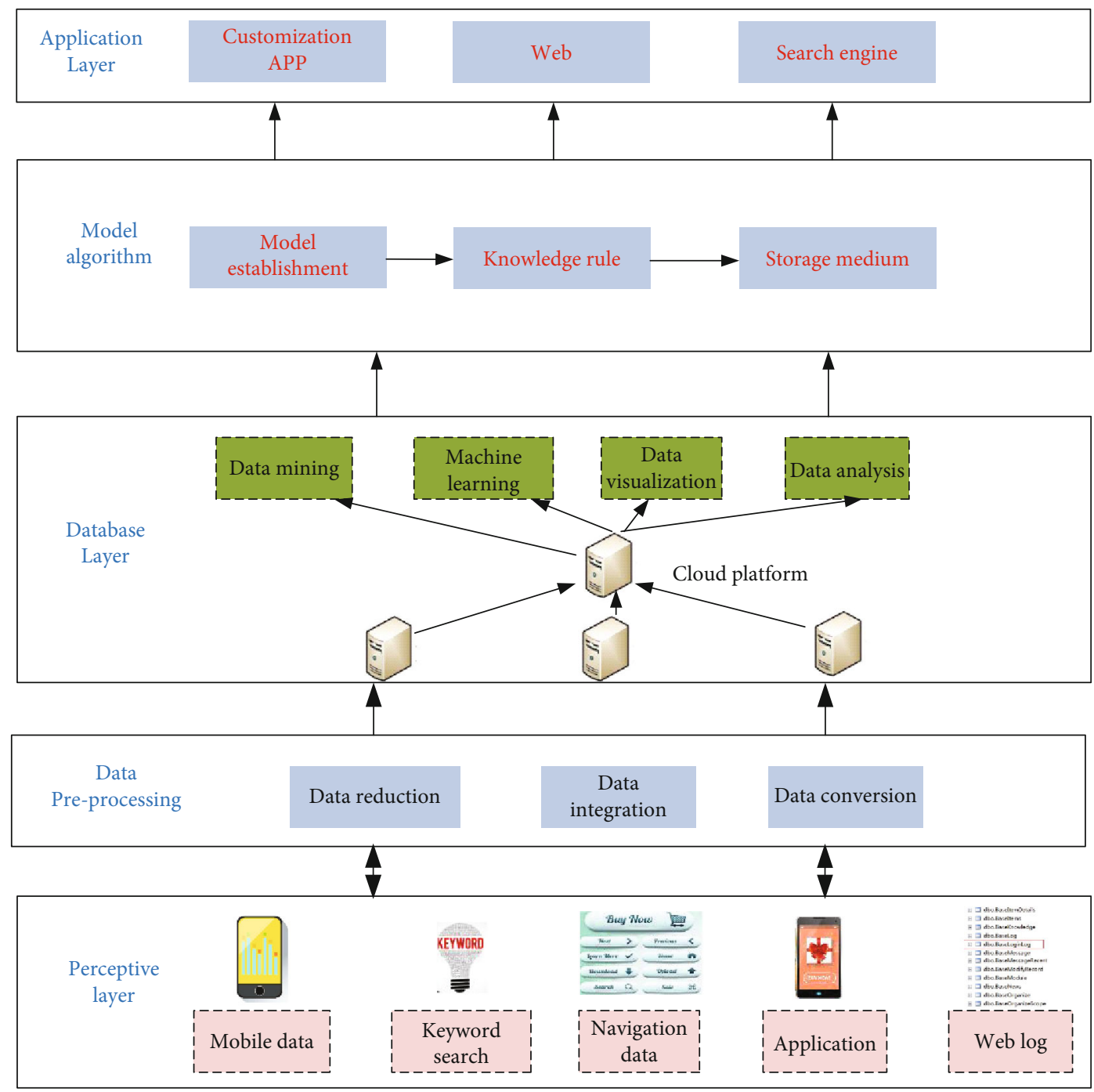

Figure 1: The intelligent tourism system architecture based on Big data technology.

with the help of past experience. It is embodied in customized services, that is, to provide a single user with the information services necessary to complete network consumption behaviour by using the known classification of consumer behaviour patterns. The mature CBR technology provides a complete set of solutions for the realization of customized services in e-commerce environment. On this basis, we give the client/server structure of customized service CBR, as shown in Figure 2. The "customization" is the abbreviation of customization service, and the algorithm is the abbreviation of rewriting algorithm.

Due to the uncertainty of the number of online customers, the scalability of the system becomes very important. The client/server architecture is used to meet this need. The client is a plug-in (such as Java Applet) that can run on a standard WWW browser, and the server includes two server modules, the control centre and the customized service (corresponding to the retrieval and rewriting of the traditional $\mathrm{CBR}$, respectively), which can be distributed on multiple computers. The typical customization service process is as follows: the client application starts, establishes a connection between the customized client and the case control centre, requests the product customization service, a control centre for customer verification, and returns the product information. The customized client submits the product information to the customized server and requests the case to rewrite the customized server. According to the product information, the algorithm server chooses the corresponding mechanism from the algorithm library to rewrite. The customized client interacts with the customized client repeatedly until the user stops the loop by accepting or rejecting the result of rewriting. The customized client returns the final result recognized by the user to the control centre for restarting.

\section{C2B Electronic Commerce Pricing Strategy considering Customized Effort}

In today's information economy era, customers need personalized products and services more and more. However, some enterprises set the same price instead of charging different consumers different prices according to their perceived consumption value, thus losing a lot of potential benefits. In fact, 


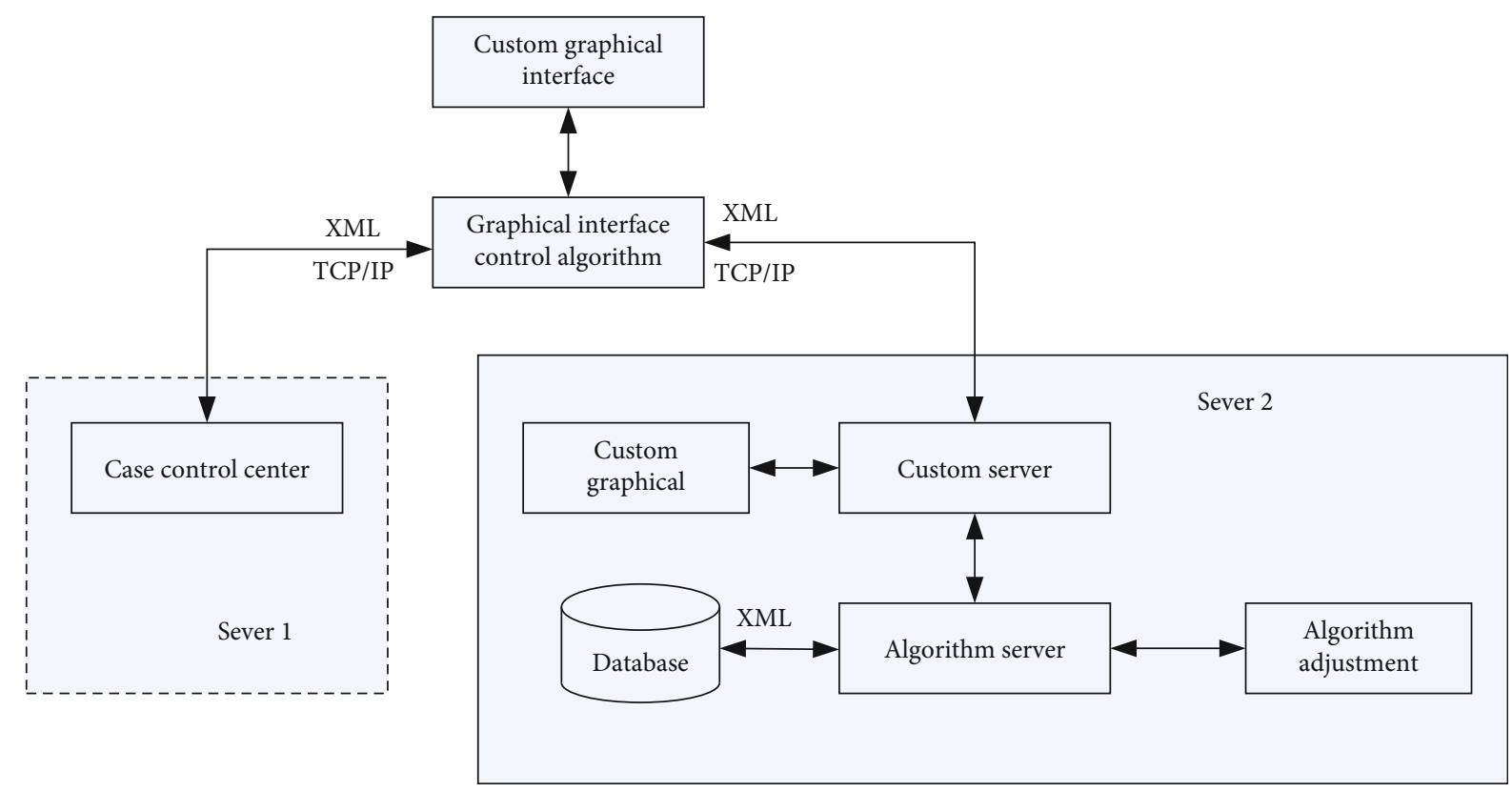

FIGURE 2: CBR architecture of customization service in electronic commerce.

different customers have a variety of needs, C2B electronic commerce (e-commerce) enterprises should adopt personalized customized pricing strategy according to actual needs; in order to improve consumer value, further expand market demand, thus greatly improving economic benefits.

Most of the traditional supply chain enterprises are affected by other supply chain members. By pricing and inventory flow, suppliers always dominate the supply chain. But with the rapid development of the economy, manufacturers and retailers are shifting their positions in the transaction, leading retailers like Carrefour, Best Buy, and Wal-Mart are rising, and their power structure in the supply chain will change accordingly. In order to survive and develop in the fierce competition, supply chain enterprises must analyze the behaviour of their competitors and make reasonable decisions according to the actual situation in order to win a place for themselves.

3.1. Mathematical Strategy Model Analysis and Symbol Description. Consider a two-echelon supply chain structure model consisting of a supplier and two manufacturers with horizontal price competition (a C2B e-commerce enterprise and a traditional enterprise). The supplier and $\mathrm{C} 2 \mathrm{~B}$ ecommerce enterprises as well as the traditional enterprises are risk-neutral, and the market demand and cost parameters are also their common information. The supplier provides general parts to $\mathrm{C} 2 \mathrm{~B}$ e-commerce enterprises and traditional enterprises at wholesale price $w$. The C2B e-commerce enterprises deliver the products to customers after individualized customization. The traditional enterprises assemble the general parts into standard products and then ship them. The retail price of individualized customized products is $p_{c}$, and the market needs it. Quantity is $D_{c}$, the retail price of standardized products is $p_{s}$, and the market demand is $D_{s}, D_{c}$ and $D_{s}$ which constitute the whole consumer market. Sup- pose $w<p_{c}, p_{s}$, otherwise, the profits of suppliers and $\mathrm{C} 2 \mathrm{~B}$ business enterprises and traditional enterprises will be zero. The $\mathrm{C} 2 \mathrm{~B}$ pricing model is shown in Figure 3.

In the demand function constructed in this paper, the market demand is fixed. The retail price $p_{c}$ of customized products has a negative impact on the demand $D_{c}$ of personalized products, a positive impact on the demand $D_{s}$ of standardized products, a negative impact on the demand $D_{s}$ of standardized products, a positive impact on the demand $D_{c}$ of personalized products, and a positive impact on the personality of products. The degree of customization effort $e$ has a positive impact on the demand for customized products and a negative impact on the demand for standardized products. The following demand functions is built as

$$
\left\{\begin{array}{l}
D_{c}=1-p_{c}+\theta p_{s}+\gamma e \\
D_{s}=1-p_{s}+\theta p_{c}-\gamma e
\end{array} .\right.
$$

In which, $\theta \in(0,1)$ represents the cross-price influence coefficient, and $\gamma \in(0,1)$ is the individualized customization effort influence coefficient. From the above demand function, we can see that the market demand $D_{c}$ is positively correlated with the degree of customization effort $e$ and the retail price $p_{s}$ of standardized products, and negatively correlated with the retail price $p_{c}$ of customized products. Market demand $D_{s}$ is positively correlated with the degree of customization effort $e$ and retail price $p_{c}$ of customized products but negatively correlated with the retail price $p_{s}$ of standardized products. The cost function of $\mathrm{C} 2 \mathrm{~B}$ business enterprise customization effort degree is

$$
c_{k}=\frac{k}{2} e^{2}
$$




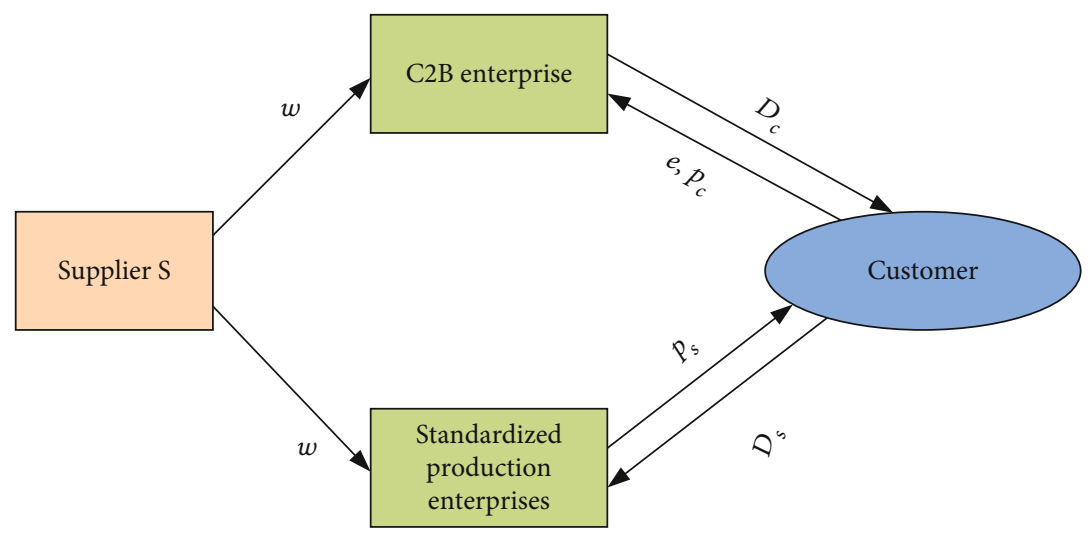

Figure 3: C2B pricing model.

In which, $k>0, c_{k}$ for personalized customization effort cost parameter. $\partial c_{k} / \partial e>0, \partial^{2} c_{k} / \partial^{2} e>0$.

3.2. Pricing Model under Centralized Decision and Its Solution. Members of the supply chain want to achieve the goal of maximizing the profit of the supply chain. When the supply chain adopts the centralized decision-making mode, the decision-maker sets the optimal degree of customization effort from the angle of maximizing the profit of the whole supply chain and, then, determines the retail price of $\mathrm{C} 2 \mathrm{~B}$ e-commerce enterprises and traditional enterprises. The total profit function of $\mathrm{C} 2 \mathrm{~B}$ supply chain is as follows:

$$
\begin{aligned}
\pi= & \left(p_{c}-w\right)\left(1-p_{c}+\theta p_{s}+\gamma e\right) \\
& +\left(p_{s}-w\right)\left(1-p_{s}+\theta p_{c}-\gamma e\right)-\frac{k}{2} e^{2} .
\end{aligned}
$$

The first derivative $p_{c}$ and $p_{s}$ can be obtained:

$$
\left\{\begin{array}{l}
1-2 p_{c}+2 \theta p_{s}+(1-\theta) w+\gamma e=0 \\
1-2 p_{s}+2 \theta p_{c}+(1-\theta) w-\gamma e=0
\end{array}\right. \text {. }
$$

In the centralized decision-making situation, the optimal pricing $p_{c}^{c d}$ and $p_{s}^{c d}$ of $\mathrm{C} 2 \mathrm{~B}$ supply chain and the optimal degree of customization effort $e^{c d}$ are as follows:

$$
\left\{\begin{array}{l}
p_{c}^{c d}=\frac{1}{2(1-\theta)}+\frac{1}{2} w \\
p_{s}^{c d}=\frac{1}{2(1-\theta)}+\frac{1}{2} w \\
e^{c d}=0
\end{array} .\right.
$$

In the centralized situation, the decision-maker has no incentive to improve the profit of the whole supply chain through the strategy of individualized customization effort. Although the profit of the whole supply chain has been maximized, consumers cannot buy customized products. In addition, we can conclude that the greater the cross-price influence coefficient, the higher the final pricing of $\mathrm{C} 2 \mathrm{~B}$ e-commerce enterprises and traditional enterprises. Secondly, there is a positive correlation between the price of products and the wholesale price of suppliers. This is because the higher the wholesale price of suppliers, the higher the purchasing cost of $\mathrm{C} 2 \mathrm{~B}$ e-commerce enterprises and traditional enterprises will be, so the supply chain enterprises will increase the price in order to achieve considerable profits. In the sense of management, $\mathrm{C} 2 \mathrm{~B}$ supply chain enterprises should not only meet the individual needs of consumers but also make the cost control of enterprises within a certain range, so as to ensure the necessary profits.

$$
\left\{\begin{array}{l}
D_{c}^{c d}=\frac{1}{2}+\frac{1}{2} w(\theta-1) \\
D_{s}^{c d}=\frac{1}{2}+\frac{1}{2} w(\theta-1) \\
\pi^{c d}=\frac{1}{2}\left(\frac{1}{1-\theta}-w\right)([1+w(\theta-1)])
\end{array} .\right.
$$

It shows that the market demand of individualized customized products is the same as that of standardized products when the centralized decision-making model is adopted. The market demand is positively correlated with wholesale price, and the influence coefficient of cross-price is also positively correlated. When the influence coefficient of cross-price rises, the market demand of products will increase. The profit of a supply chain is increased.

3.3. Pricing Model and Solution under Decentralized Decision-Making. When decentralized decisions are made, supply chain members are independent individuals. Different from centralized decision-making, C2B e-commerce enterprises and traditional enterprises have different interests in decentralized decision-making. $\mathrm{C} 2 \mathrm{~B}$ e-commerce enterprises first determine the degree of individual customization effort $e$ , and then, the two enterprises determine the retail prices of two different products $p_{s}$ and $p_{c}$ at the same time. In this case, it can be concluded that the profit function of $\mathrm{C} 2 \mathrm{~B}$ business enterprise and traditional enterprise are 


$$
\left\{\begin{array}{l}
\pi_{c}^{n l}=\left(p_{c}-w\right)\left(1-p_{c}+\theta p_{s}+\gamma e\right)-\frac{k}{2} e^{2} \\
\pi_{s}^{n l}=\left(p_{s}-w\right)\left(1-p_{s}+\theta p_{c}-\gamma e\right)
\end{array} .\right.
$$

Under the independent and simultaneous decisionmaking of $\mathrm{C} 2 \mathrm{~B}$ e-commerce enterprises and traditional enterprises, the optimal pricing $p_{c}^{n l}$ and $p_{s}^{n l}$ of supply chain members and the optimal degree of customization effort $e^{n l}$ are as follows:

$$
\left\{\begin{array}{l}
p_{c}^{n l}=\frac{(w+1)\left[k(2+\theta)^{2}-2 \gamma\right]+2 \gamma^{2}(1+\theta w-w)}{(2-\theta)\left[k(2+\theta)^{2}-2 \gamma\right]} \\
p_{s}^{n l}=\frac{(w+1)\left[k(2+\theta)^{2}-2 \gamma\right]-2 \gamma^{2}(1+\theta w-w)}{(2-\theta)\left[k(2+\theta)^{2}-2 \gamma\right]} \\
e^{n l}=\frac{2 \gamma(1+\theta w-w)(2+\theta)}{(2-\theta)\left[k(2+\theta)^{2}-2 \gamma\right]}
\end{array}\right.
$$

3.4. Pricing Model and Solution of C2B Business Enterprise Dominated Decision-Making. Considering that C2B ecommerce enterprises which provide customized products play a dominant role, they make decisions first, while traditional enterprises which provide standardized products to consumers follow suit, and the two enterprises make decisions individually. In the model of this section, $\mathrm{C} 2 \mathrm{~B}$ ecommerce enterprises and traditional enterprises constitute a three-stage sequential game model. In the first stage, C2B e-commerce enterprises determine the degree of effort to customize the product personalized in the second stage, $\mathrm{C} 2 \mathrm{~B}$ e-commerce enterprises according to the actual situation to determine the price of customized products $p_{c}$; in the third stage, traditional enterprises determine the price of standardized products $p_{s}$. From this, we get the pricing decision timing of the $\mathrm{C} 2 \mathrm{~B}$ supply chain. In this case, it can be concluded that the profit function of $\mathrm{C} 2 \mathrm{~B}$ business enterprise and traditional enterprise are

$$
\left\{\begin{array}{l}
\pi_{c}^{c s}=\left(p_{c}-w\right)\left(1-p_{c}+\theta p_{s}+\gamma e\right)-\frac{k}{2} e^{2} \\
\pi_{s}^{c s}=\left(p_{s}-w\right)\left(1-p_{s}+\theta p_{c}-\gamma e\right)
\end{array} .\right.
$$

$\mathrm{C} 2 \mathrm{~B}$ e-commerce enterprises first determine the degree of personalized effort of the product $e^{c s}$, and then according to the actual situation to determine the price of personalized customized products $p_{c}$, and finally the traditional enterprise to determine the price of standardized products to consumers $p_{s}$. In this paper, the C2B supply chain model is solved by the inverse induction method of dynamic game. The following conclusions can be drawn. Under the dominant decision-making of $\mathrm{C} 2 \mathrm{~B}$ business enterprises, the degree of individualized customization of supply chain members is

$$
e^{c s}=\frac{(2-\theta)[2+\theta(w+1)] \gamma-w(2-\theta)\left(2-\theta^{2}\right) \gamma}{4 k\left(2-\theta^{2}\right)-(2-\theta)^{2} \gamma} .
$$

3.5. The Pricing Model and Solution of Traditional Enterprise Dominated Decision-Making. Considering the dominance of traditional enterprises providing standardized products, $\mathrm{C} 2 \mathrm{~B}$ e-commerce enterprises that provide customized products to consumers first make decisions, and then, the two enterprises make decisions individually. In the model of this section, $\mathrm{C} 2 \mathrm{~B}$ e-commerce enterprises and traditional enterprises constitute a three-stage sequential game model. In the first stage, $\mathrm{C} 2 \mathrm{~B}$ enterprises determine the degree of individualized effort $e$; in the second stage, the traditional enterprises determine the price PS of standardized products; in the third stage, $\mathrm{C} 2 \mathrm{~B}$ e-commerce enterprises determine the price PC of personalized customized products according to the actual situation.

In this case, it can be concluded that the profit function of $\mathrm{C} 2 \mathrm{~B}$ business enterprise and traditional enterprise are

$$
\left\{\begin{array}{l}
\pi_{c}^{t s}=\left(p_{c}-w\right)\left(1-p_{c}+\theta p_{s}+\gamma e\right)-\frac{k}{2} e^{2} \\
\pi_{s}^{t s}=\left(p_{s}-w\right)\left(1-p_{s}+\theta p_{c}-\gamma e\right)
\end{array} .\right.
$$

Firstly, C2B e-commerce enterprises determine the degree of individual effort $e^{t s}$; then, the traditional enterprises determine the price $p_{s}$ of standardized products they provide to consumers, and finally, $\mathrm{C} 2 \mathrm{~B}$ e-commerce enterprises determine the price $p_{c}$ of customized products according to the actual situation. Reverse induction is still used to solve the C2B supply chain model.

The customization effort $e^{t s}$ of supply chain members can be expressed as

$$
e^{t s}=\frac{2 U S \gamma+(\theta-2) w \gamma S T}{4 k T^{2}-2 S^{2} \gamma^{2}},
$$

where $S=-\theta^{2}-2 \theta+4, T=4-2 \theta^{2}, U=-\theta^{2}+2 \theta+4+$ $\theta^{2} w$

\section{Simulation Results and Discussion}

Because the expression of equilibrium decision of supply chain members is very complicated in some situations, it is difficult to get intuitive conclusions. In order to further analyze the relationship between the variables, this section simplifies the model by assuming that the degree of customization effort $e$ is a parameter. Comparing four different decision situations of supply chain members under C2B scenario is conducted in this section.

4.1. The Influence of Cross-Price Influence Coefficient on Decision Equilibrium. Based on the basic model proposed in this paper, the simulation is carried out in the subsection. Considering $e$ as the decision variable, the parameters are assigned as follows according to the actual situation of the enterprise: $w=0.5, \gamma=1$, and $k=1$.

The study did not affect the degree of customization effort $e$. Figure 4 shows that in three different scenarios, with no increase, that is, the more intense price competition, C2B e-commerce enterprises personalized customization 


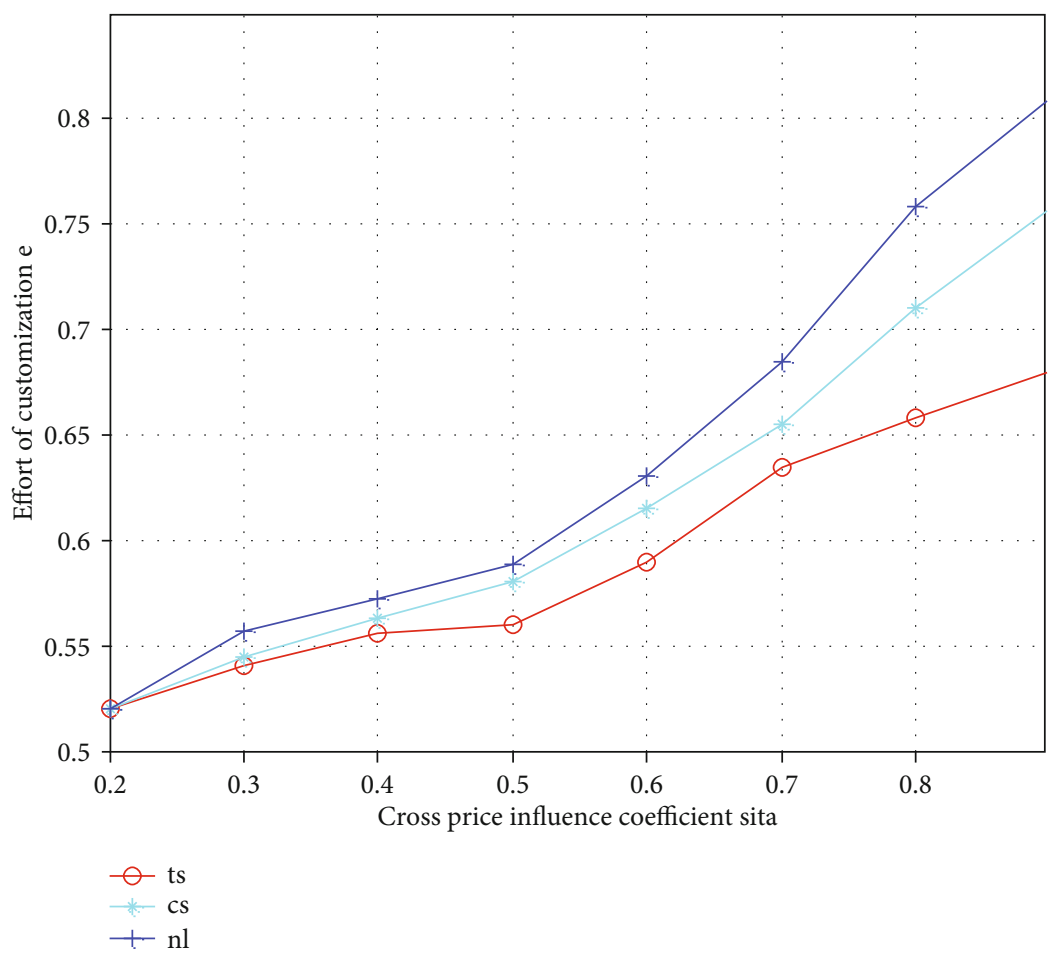

FIgURE 4: Influence of cross-price influence coefficient $\theta$ on decision equilibrium.

efforts have increased. This is very understandable, C2B ecommerce enterprises perceive fierce price competition, will set a higher degree of customization efforts to achieve product differentiation, in order to obtain customer orders. It is worth noting that under the $\mathrm{C} 2 \mathrm{~B}$ e-commerce-dominated situation, $\mathrm{C} 2 \mathrm{~B}$ e-commerce enterprise personalized customization efforts to improve faster, because in this situation, $\mathrm{C} 2 \mathrm{~B}$ e-commerce enterprises have the dominant power in price competition, which can better use personalized customization to win the favour of customers.

4.2. The Impact of $\theta$ on Standardized Price and Customization Price. Consider the impact of $\theta$ on product prices. From Figures 5 to 6 , we can see that the price of customized products and standardized products will increase with the increase of cross-price impact coefficient. There is no positive correlation between the price of the product and the increase in the price of $\theta$. The price of standardized products under centralized decision-making mode is the highest, and the price under decentralized decision-making and e-commerce-led mode is higher than that under traditional enterprise-led mode, respectively. The price of standardized products is the lowest under traditional enterprise-dominated situation. The reason for this phenomenon may be that traditional enterprises want to take advantage of their dominant advantages and adopt low price. The competitive strategy of price marketing has won the favour of more consumers.

4.3. The Impact of $\theta$ on Standardized Demand and Customization Demand. Consider the impact of $\theta$ on product demand. From Figures 7 to 8 , we can see that with the increase of cross-price impact coefficient, the demand for personalized customized products and standardized products will increase. From Figure 7, we can see that the demand of customized products is the biggest when traditional enterprises are dominant. The demand of products increases with the increase of $\theta$. The larger $\theta$, the faster the demand is rising. From Figure 8, we can see that the demand for standardized products is the smallest when traditional enterprises are dominant and the demand for standardized products increases slowly when centralized decision-making is taken. This shows that the change of 0 at this time has a weak impact on product demand. When the cross-price influence coefficient is higher than a certain threshold $(\theta>0.425)$, the demand for products in decentralized decision-making scenario is the largest, and when it is not in a certain interval $(0<\theta<0.425)$, the demand for products in centralized decision-making scenario is the largest. When it is higher than a certain threshold $(\theta>0.67)$, when $\mathrm{C} 2 \mathrm{~B}$ e-commerce enterprises dominate, the market demand of standardized products is larger than that of centralized decision-making situation, which shows that $\theta$ has a greater driving force for product demand in this context.

4.4. The Impact of $\theta$ on Profit of e-Commerce Enterprises and Traditional Enterprises. As shown in Figure 9, with the increase of $\mathrm{x}$, the profits of $\mathrm{C} 2 \mathrm{~B}$ e-commerce enterprises grow rapidly in three different situations, but they are the most profitable under the traditional enterprise-led situation, which is very interesting. This shows that, although $\mathrm{C} 2 \mathrm{~B}$ ecommerce enterprises cannot bring high profits by dominating price competition, they are more profitable to become followers in pricing. This is because, although the price of 


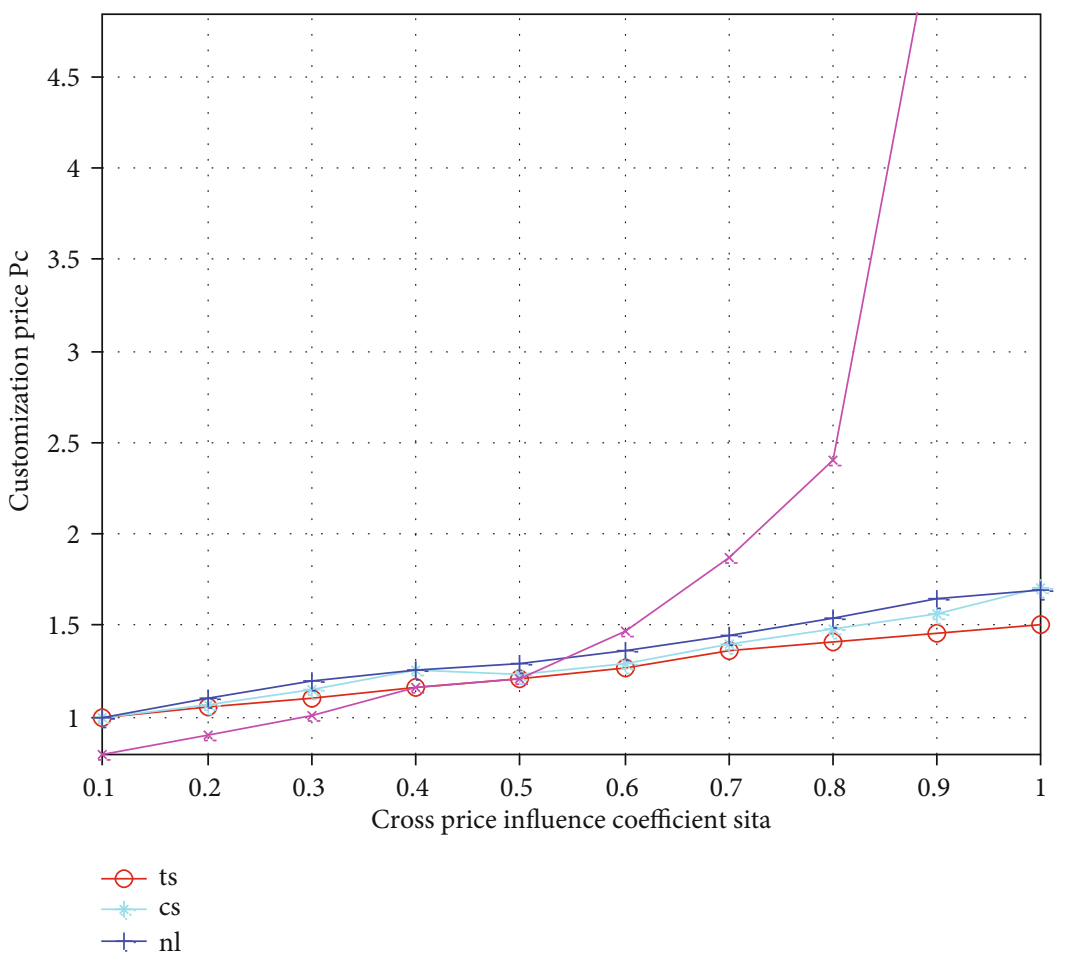

FIGURE 5: The impact of $\theta$ on standardized price.

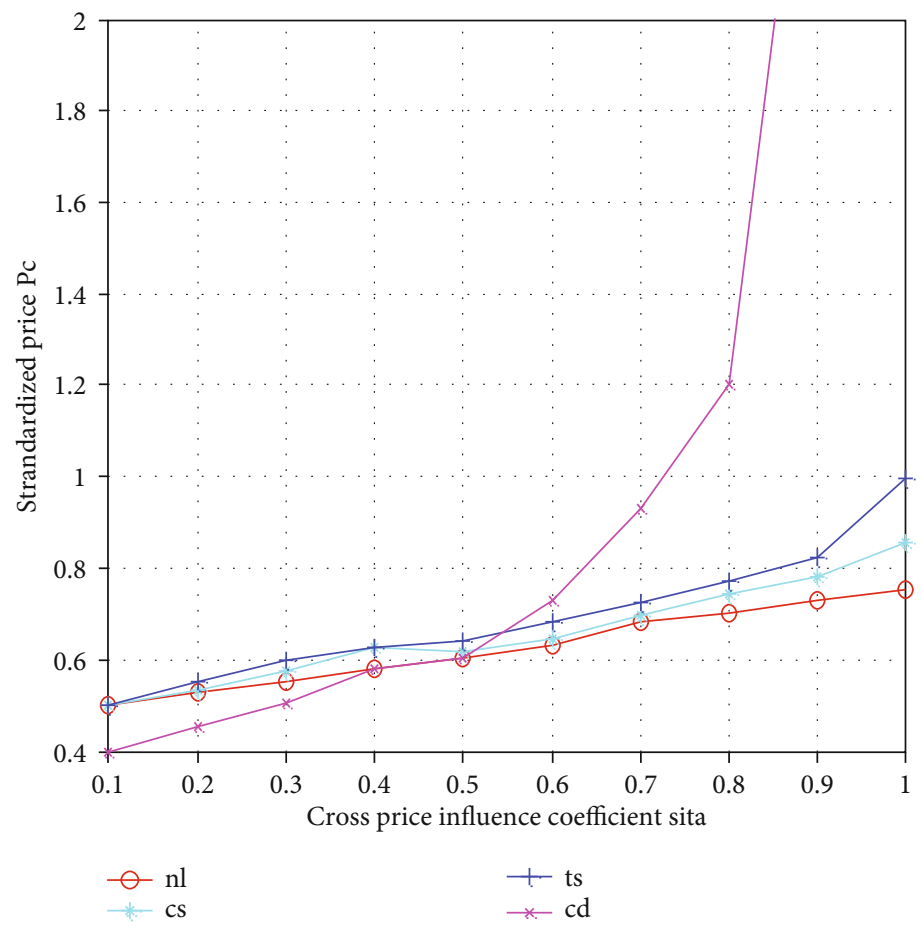

Figure 6: The impact of $\theta$ on the price of customization price.

personalized products is higher and the unit profit is increased under the $\mathrm{C} 2 \mathrm{~B}$-dominated situation, the demand falls greatly, so the profit is smaller than that under the traditional enterprise-dominated situation.
As is shown in Figure 10, the profit of traditional enterprises is positively correlated with $\mathrm{X}$. When traditional enterprises are dominant, the profit of standardized products is the largest, while the profit of traditional enterprises is the 


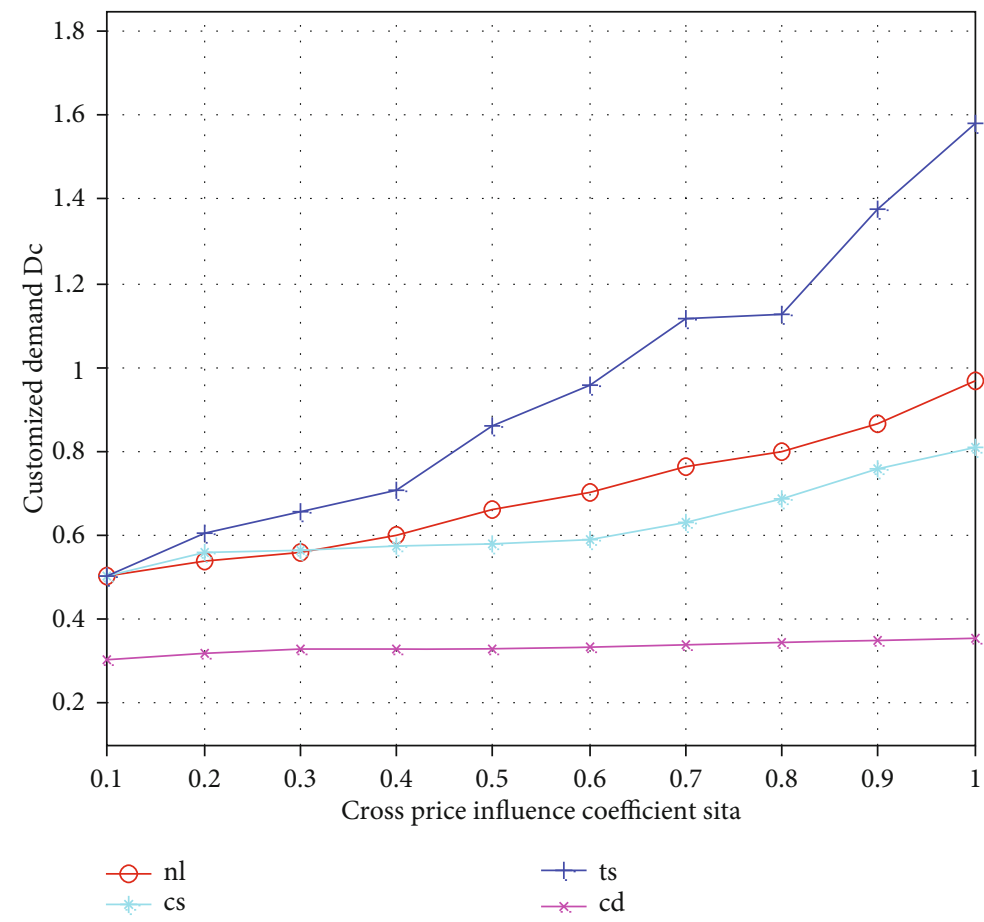

Figure 7: The impact of $\theta$ on standardized demand.

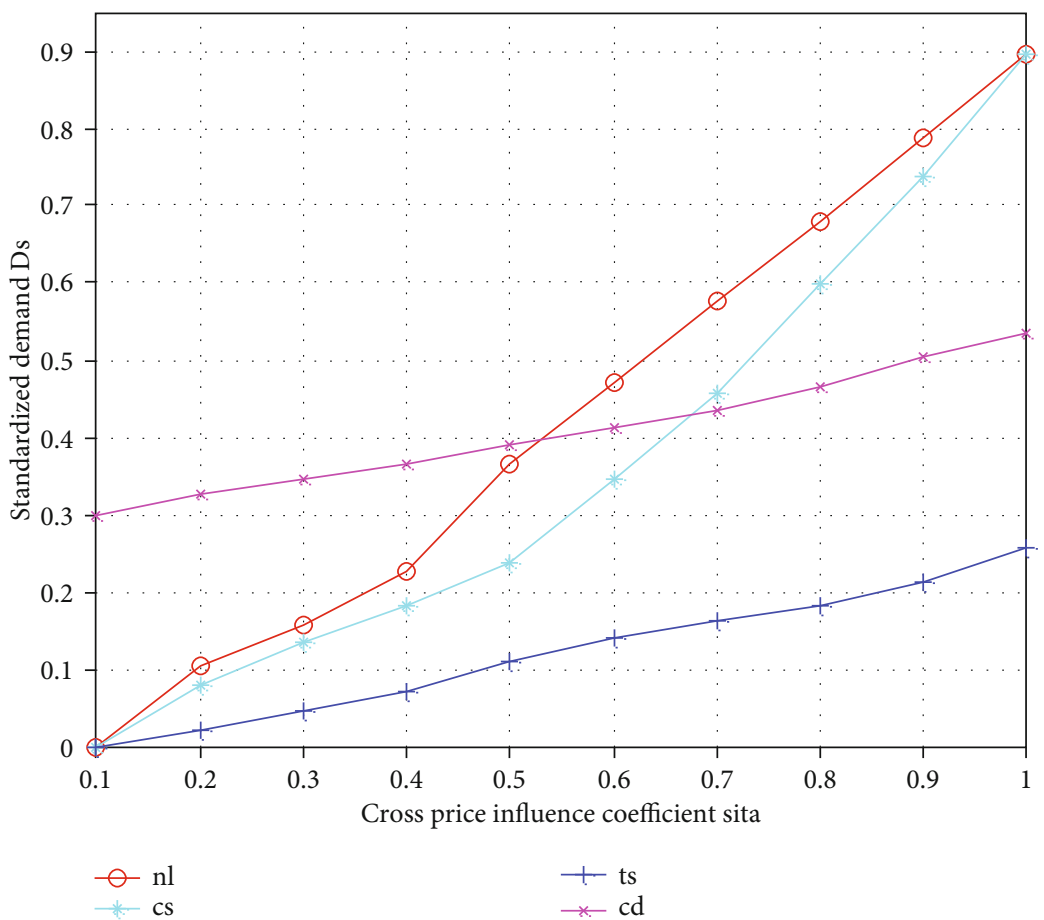

Figure 8: The impact of $\theta$ on the price of customization demand.

lowest under decentralized decision-making. And the bigger the $\mathrm{X}$, the more profitable it will be to promote the growth of traditional business profits.

It is worth noting that, compared with other scenarios, the profits of $\mathrm{C} 2 \mathrm{~B}$ e-commerce enterprises and traditional enterprises are lower in both independent and simultaneous decision-making scenarios, which show that when choosing reasonable pricing strategies, enterprises should also pay attention to cooperation and competition, rather than relying solely on their own single enterprise to compete with many enterprises. After all, in the fierce market competition, the dominant situation on one side will not last long. In order 


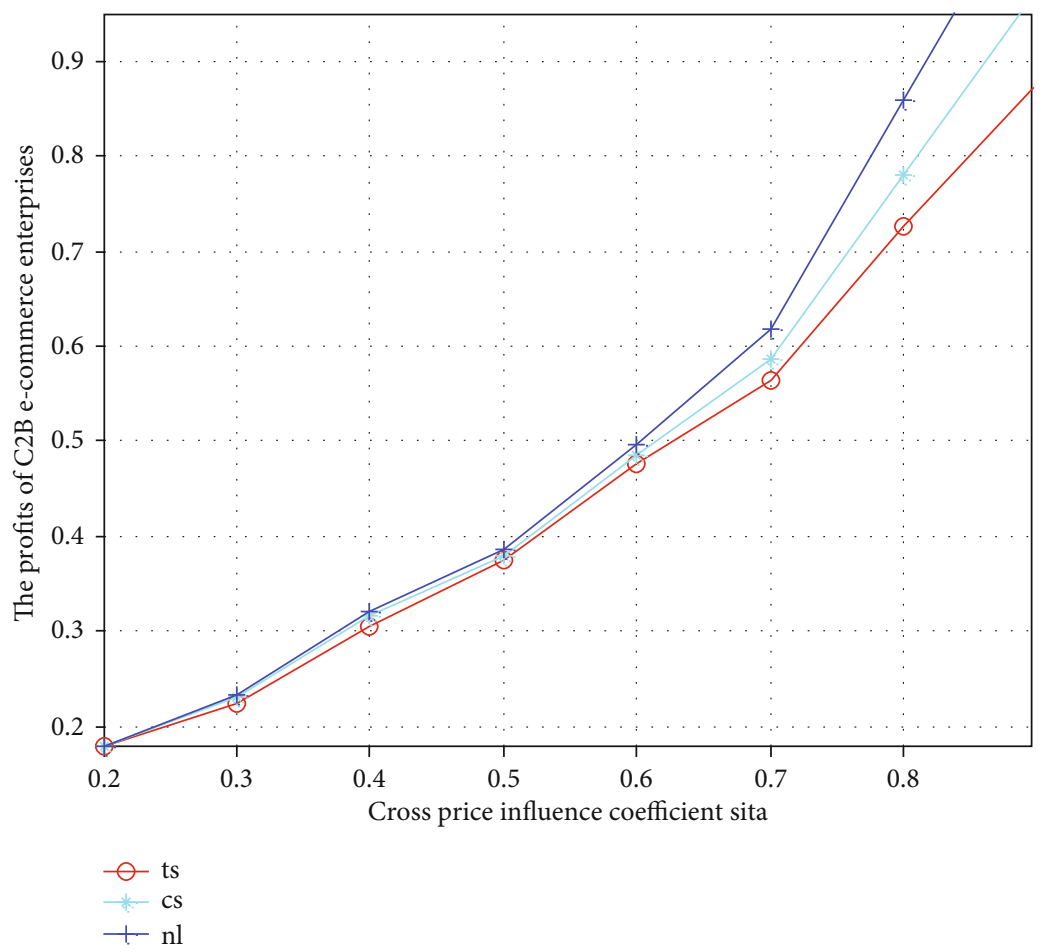

Figure 9: The impact of $\theta$ on the profits of $\mathrm{C} 2 \mathrm{~B}$ e-commerce enterprises.

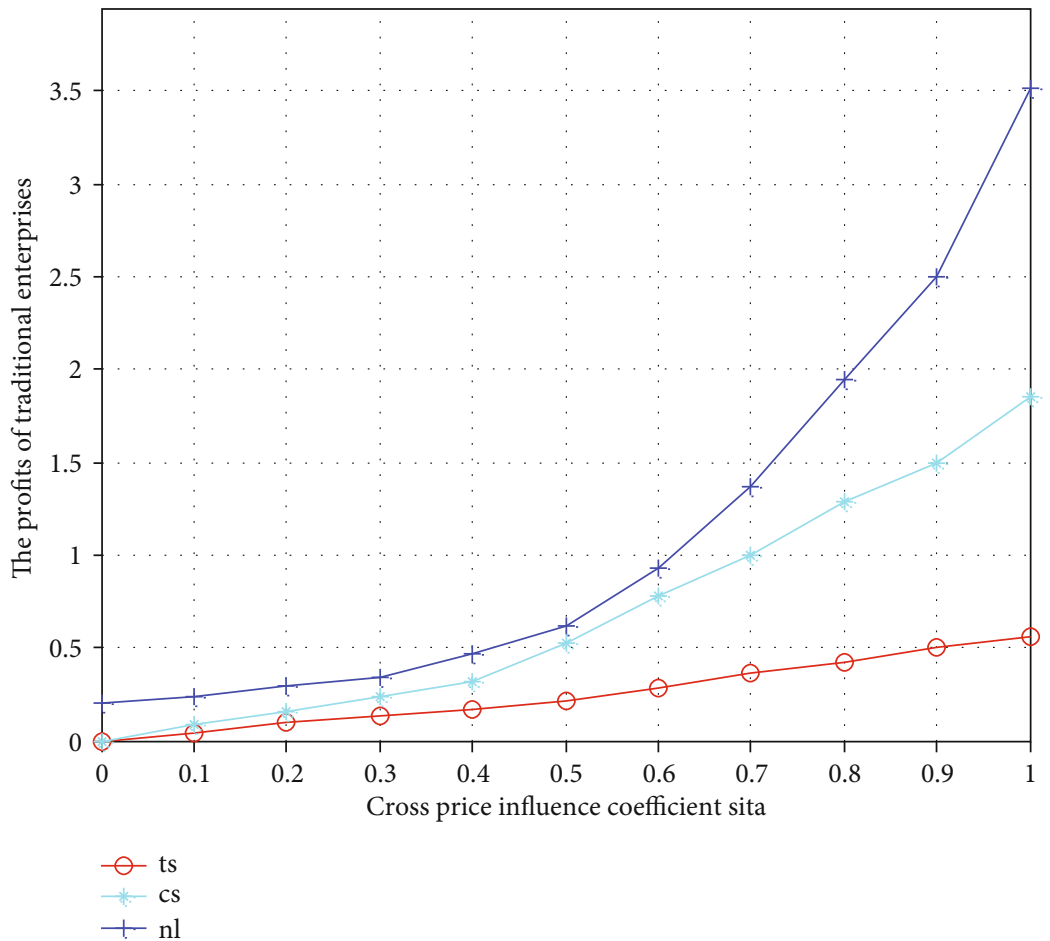

Figure 10: The impact of $\theta$ on the profits of traditional enterprises.

to remain invincible in the cruel competition, enterprises and competitors should maintain the spirit of both competition and mutual learning and cooperation, and constantly innovate to meet the needs of more consumers.

\section{Conclusion}

The continuous development and expansion of e-commerce market has brought many business opportunities to the 
market, and also brought different degrees of negative impact. In an age of computer development is very rapid, large data network technology to every aspect of life brings a lot of change, this article discussed the electronic commerce strategy research based on the technology of network data, through the study of game balance four members of the supply chain scenario: centralized decision-making and decentralized decision-making, C2B-dominated decision-making, and traditional enterprise-dominated in the enterprise applications; finally, it is concluded that the e-commerce market of big data based on Internet can develop healthier, whether the data storage and analysis of the research can be more efficient. This method can bring important development function to the electronic commerce market.

\section{Data Availability}

All data are true and reliable, and all data can be obtained by contacting the author.

\section{Conflicts of Interest}

The authors declare that they have no conflicts of interest.

\section{References}

[1] W. Liu, Y. Yang, S. Wang, and E. Bai, "A scheduling model of logistics service supply chain based on the time windows of the FLSP's operation and customer requirement," Annals of Operations Research, vol. 257, no. 1-2, pp. 183-206, 2017.

[2] Q. Tu, M. A. Vonderembse, and T. S. Ragu-Nathan, "The impact of time-based manufacturing practices on mass customization and value to customer," Journal of Operations Management, vol. 19, no. 2, pp. 201-217, 2001.

[3] Y. Wang, E. Zio, X. Wei, D. Zhang, and B. Wu, “A resilience perspective on water transport systems: the case of eastern star," International Journal of Disaster Risk Reduction, vol. 33, no. 1, pp. 343-354, 2019.

[4] Z. Chen, Y. Zhang, C. Wu, and B. Ran, "Understanding individualization driving states via latent Dirichlet allocation model," IEEE Intelligent Transportation Systems Magazine, vol. 11, no. 2, pp. 41-53, 2019.

[5] R. Aron, A. Sundararajan, and S. Viswanathan, "Intelligent agents in electronic markets for information goods: customization, preference revelation and pricing," Decision Support Systems, vol. 41, no. 4, pp. 764-786, 2006.

[6] Y. Wang and D. Li, "Testing the moderating effects of toolkits and user communities in personalization: the case of social networking service," Decision Support Systems, vol. 55, no. 1, pp. 31-42, 2013.

[7] S. Rosaci and G. M. L. Sarné, "Recommending multimedia web services in a multi-device environment," Information Systems, vol. 38, no. 2, pp. 198-212, 2013.

[8] Z. Ning, X. Kong, F. Xia, W. Hou, and X. Wang, "Green and sustainable cloud of things: enabling collaborative edge computing," IEEE Communications Magazine, vol. 57, no. 1, pp. 72-78, 2018.

[9] S. Afshin Mansouri, D. Gallear, and M. H. Askariazad, "Decision support for build-to-order supply chain management through multiobjective optimization," International Journal of Production Economics, vol. 135, no. 1, pp. 24-36, 2012.
[10] J. H. Park and S. C. Park, "Agent-based merchandise management in business-to-business electronic commerce," Decision Support Systems, vol. 35, no. 3, pp. 311-333, 2003.

[11] K. Li and T. C. Du, "Building a targeted mobile advertising system for location-based services," Decision Support Systems, vol. 54, no. 1, pp. 1-8, 2012.

[12] S. Kortmann, C. Gelhard, C. Zimmermann, and F. T. Piller, "Linking strategic flexibility and operational efficiency: the mediating role of ambidextrous operational capabilities," Journal of Operations Management, vol. 32, no. 7-8, pp. 475-490, 2014.

[13] I. G. Dino and R. Stouffs, "Evaluation of reference modeling for building performance assessment," Automation in Construction, vol. 40, no. 4, pp. 44-59, 2014.

[14] M. Zhang, D. Zhang, F. Goerlandt, X. Yan, and P. Kujala, "Use of HFACS and fault tree model for collision risk factors analysis of icebreaker assistance in ice-covered waters," Safety Science, vol. 111, pp. 128-143, 2019.

[15] T. Yuan and O. Joon, "Research on credit scoring of Chinese listed SMEs based on DEA method," Credit, vol. 32, no. 6, pp. 52-56, 2014. 